The International
Journal of Tuberculosis
and Lung Disease

Time for men to count, too

\begin{tabular}{|c|c|}
\hline Journal: & The International Journal of Tuberculosis and Lung Disease \\
\hline Manuscript ID & IJTLD-12-15-1031 \\
\hline Manuscript Type: & Correspondence \\
\hline Date Submitted by the Author: & 30-Dec-2015 \\
\hline Complete List of Authors: & $\begin{array}{l}\text { Horton, Katherine; London School of Hygiene and Tropical Medicine, } \\
\text { Department of Clinical Research; London School of Hygiene and Tropical } \\
\text { Medicine, Tuberculosis Modelling Group, Tuberculosis Centre } \\
\text { Houben, Rein; London School of Hygiene and Tropical Medicine, } \\
\text { Department of Infectious Disease Epidemiology; London School of Hygiene } \\
\text { and Tropical Medicine, Tuberculosis Modelling Group, Tuberculosis Centre } \\
\text { White, Richard; LSHTM, Department of Infectious Disease Epidemiology; } \\
\text { London School of Hygiene and Tropical Medicine, Tuberculosis Modelling } \\
\text { Group, Tuberculosis Centre } \\
\text { Corbett, Elizabeth; Malawi-Liverpool-Wellcome Trust Clinical Research } \\
\text { Programme, TB Research Unit; London School of Hygiene and Tropical } \\
\text { Medicine, Department of Clinical Research }\end{array}$ \\
\hline Key Words: & Tuberculosis, Treatment outcome, Gender, Men, Women \\
\hline
\end{tabular}




\section{Time for men to count, too}

In a recent issue of the Journal, Kosgei et al. report gender differences in treatment outcomes among 15-49 year olds with smear-positive pulmonary tuberculosis (TB) in Kenya. We applaud the formal analysis of routine programme data to examine treatment outcomes and appreciate the authors' interest in assessing these outcomes by gender. These analyses are important since the World Health Organization does not currently collect or report data on treatment outcomes by gender.

However, we question the interpretation of some of the study's findings. Although women were slightly more likely to experience poor treatment outcomes (treatment failure or death) than men ( $12 \%$ vs. $10 \%$ ), women were considerably more likely than men to be infected with HIV ( $41 \%$ vs. 25\%). Analyses stratified by human immunodeficiency virus (HIV) or antiretroviral therapy (ART) status show that the odds ratios of poor treatment outcomes in women compared men ranged from 0.89 to 1.16 . In all stratified analyses confidence intervals include zero (the null value) and so should be interpreted as showing no significant difference (or similar risk) of poor treatment outcomes in men and women once differences in HIV/ART status have been taken into account.

Also notable is the restriction to patients with a definitive treatment outcome, thus excluding an unspecified number of registered patients who were lost to follow-up or interrupted treatment. Studies have consistently shown that a high proportion of patients lost to follow-up are in fact dead. Moreover, men are more likely than women to be lost to follow-up during treatment. We wonder if this may have contributed to the unusually low relative risk of death among male patients in this study, since reported treatment outcomes tend to be worse for men than women in other settings, as referenced by the authors [1-3]. As such, it would be of special interest to know the number and gender distribution of individuals excluded due to loss to follow-up in order to assess the potential for underestimation of male deaths in this patient group.

Gender is a significant issue that needs to be addressed in TB prevention and care, and it is important to monitor gender differences in treatment outcomes and throughout the TB care pathway. However, in evaluating gender differences, we feel it is important to break with the convention that focuses 
almost entirely on women. Globally, $65 \%$ of adult TB deaths occur among men [4], and we must be mindful that this half of the population is not marginalised from our analyses, discussions and intervention strategies.

Katherine C. Horton*†

Rein M.G.J. Houben†t

Richard G. Whitett

Elizabeth L. Corbett*\$

* Department of Clinical Research, London School of Hygiene and Tropical Medicine, London, United Kingdom

$\uparrow$ Tuberculosis Modelling Group, Tuberculosis Centre, London School of Hygiene and Tropical

Medicine, London, United Kingdom

$\$$ Department of Infectious Disease Epidemiology, London School of Hygiene and Tropical

Medicine, London, United Kingdom

$\S$ Malawi-Liverpool-Wellcome Trust Clinical Research Programme, Blantyre, Malawi

\section{References}

1. Feng JY, Huang SF, Ting WY, Chen YC, Lin YY, et al. (2012) Gender differences in treatment outcomes of tuberculosis patients in Taiwan: A prospective observational study. Clinical Microbiology and Infection 18: E331-E337.

2. Jimenez-Corona ME, Garcia-Garcia L, DeRiemer K, Ferreyra-Reyes L, Bobadilla-Del-Valle M, et al. (2006) Gender differentials of pulmonary tuberculosis transmission and reactivation in an endemic area. Thorax 61: 348-353.

3. Mukherjee A, Saha I, Sarkar A, Chowdhury R (2012) Gender differences in notification rates, clinical forms and treatment outcome of tuberculosis patients under the RNTCP. Lung India 29: $120-122$.

4. World Health Organization (2015) Global tuberculosis report 2015. Geneva, Switzerland: World Health Organization. 